\title{
Uranyl Acetate Staining Method
}

National Cancer Institute

\section{Source}

National Cancer Institute. Uranyl Acetate Staining Method. NCI Thesaurus. Code C92303.

A microscopy staining method that utilizes uranyl acetate, a water insoluble yellow crystalline solid, which is used as a negative stain in electron microscopy. 